\title{
Intentional tanning behaviors among undergraduates on the United States' Gulf Coast
}

\author{
Casey L. Daniel ${ }^{1 *} \mathbb{D}$, Natalie R. Gassman', Alyssa M. Fernandez', Sejong Bae 2,3 and Marcus C. B. Tan ${ }^{4}$
}

\begin{abstract}
Background: Rates of melanoma have dramatically increased among adolescents and young adults in recent years, particularly among young women. Exposure to ultraviolet radiation from intentional tanning practices is likely a major contributor to this epidemic. Southern and coastal regions have higher melanoma mortality rates among non-Hispanic whites in other parts of the U.S., yet little is known about tanning practices of adolescents and young adults in these regions. This study determines the prevalence and methods of intentional tanning utilized by an undergraduate population located on the United States' Gulf Coast.

Methods: Undergraduate students enrolled at a university on the Gulf Coast completed an online survey from March-April 2016, self-reporting their engagement, knowledge, and attitudes regarding outdoor tanning (OT), indoor tanning (IT) and spray tanning (ST). Univariate and multivariate analyses were performed to identify factors associated with tanning behaviors.
\end{abstract}

Results: 2668 undergraduates completed the survey. Of these, 64.9\% reported OT tanning, 50.7\% reported ever IT, and $21.2 \%$ reported ever ST.

Conclusions: In the largest study to date of intentional tanning behaviors of adolescents and young adults from coastal regions, we found high rates of intentional tanning behaviors. There was also significant engagement in spray tanning by this population, not previously reported for adolescents and young adults in a sample of this size. We also identified a high association between different tanning methods, indicating this population engages in multiple tanning behaviors, a phenomenon whose health consequences are not yet known.

Keywords: Adolescent, Young adult, Tanning, Skin cancer, Melanoma, Prevention

\section{Background}

The incidence of skin cancers, especially melanoma, continues to rise, particularly among adolescents and young adults (AYA) [1-3]. The most significant and modifiable risk factor for the development of cutaneous malignancies is ultraviolet (UV) radiation exposure [1, 4-8]. In the AYA population, recreational UV exposure (tanning) is a popular activity [9-15], driven primarily by the perceived social desirability of a tanned appearance [16-20]. The most common methods of tanning are outdoor tanning (OT) and indoor tanning (IT),

\footnotetext{
*Correspondence: cldaniel@health.southalabama.edu

'Division of Oncological Sciences, University of South Alabama Mitchell

Cancer Institute, 1660 Springhill Avenue, Mobile, AL 36604, USA

Full list of author information is available at the end of the article
}

though non-UV based tanning methods such as spray tanning (ST) are increasingly popular, since they are promoted as a safer alternative to OT and IT [13].

In recent years, numerous studies have examined tanning behaviors in college students. However, these have mostly focused on colleges in the Northeastern and Midwestern regions of the U.S. [9, 10, 21-25]. None of the studies at Southern U.S. colleges have examined all three tanning modalities and their relative frequencies $[12,16,26,27]$. Developing a comprehensive understanding of tanning behaviors of Southern college students is important for a number of reasons: skin cancer risk increases with the North-South UV index gradient [28]; Southern states receive the highest amount of UV radiation reaching the earth's surface [28], individuals 
residing in Southern and coastal regions have the highest mortality rates among non-Hispanic whites [29], national high school student data suggests that tanning behaviors are highest in the South compared with other geographies [30], and proximity to beaches in Southern states has been noted as a motivator for selecting a college along the coast [26]. Therefore, this study sought to investigate all types of intentional tanning behaviors at a coastal university in the South.

\section{Methods}

\section{Participants and survey administration}

Participants were undergraduate students enrolled at a public, state university in Mobile, Alabama. Eligibility criteria for study participation were: age 18 years or older and enrollment at the participating institution. Institutional Review Board approval was obtained prior to data collection. All students enrolled at the institution were sent an email to their university email addresses containing a brief description and link to the survey in March 2016. Subsequent reminders were sent once per week for the following three weeks. Research Electronic Data Capture (REDCap) was used to create a survey and data collection. Students were given a written explanation of informed consent detailing the anonymity of participation upon initiation of the electronic survey. The first 2000 students to complete the survey received an incentive of a \$5 USD gift card to Amazon.com, which was distributed electronically.

\section{Outcome measures}

Primary outcome measures were self-reported current OT and/or ever use of: a) IT; and/or b) ST. OT was defined by questions asking if the respondent tanned outdoors year round and/or in what seasons. IT was defined by the question, "Have you ever used a tanning bed before?" ST was defined by the question, "Have you ever gotten a spray tan?" Our explanatory measures included demographics (age, college year, sex, race, and family melanoma history); Fitzpatrick skin type (scores determined by responses to natural hair color, natural eye color, color of untanned skin, number of freckles, burn tendency, and tan tendency) [31]; attitudinal variables; and risk perceptions. Attitudinal and risk perception questions were not included in the current analysis.

For race, categories: American Indian or Alaska native; Asian; Hispanic or Latino; Other; and multiracial were combined to form the "Other" option due to small sample sizes and categorized as: 'White,' 'Black or African American', and 'Other.' Fitzpatrick categories were also combined due to low sample sizes in each response and categorized as: 'Fitzpatrick Type I/II,' 'Fitzpatrick Type III,' 'Fitzpatrick Type IV,' 'Fitzpatrick Type V/VI.'

\section{Statistical analysis}

Frequencies and percentages were calculated for categorical variables. Binary logistic regressions were utilized to examine relationships between demographic and aforementioned characteristics and the tanning behaviors of interest (OT, IT, and ST). We estimated both unadjusted and adjusted odds ratios (OR) and their corresponding 95\% confidence intervals (95\% CI) using logistic regression analyses. Multicollinearity of covariates was assessed using the variance inflation factor threshold of 5 . Statistical analyses were performed using SAS v9.4, where statistical significance was considered if $P$-values were less than 0.05 .

\section{Results}

Of the 10,880 undergraduates contacted, 2668 students completed the survey (24.5\% response rate, comparable to other electronic surveys) [32, 33]. The majority of respondents were female (69.3\%) and White (68.9\%). These respondents reflect the larger campus population, of which $61.5 \%$ are female and $61.1 \%$ are White. Most participants were upperclassmen: freshman (20.8\%); sophomore (22.1\%); junior (27.1\%); senior (30.0\%). Rates of response by class year were also comparable to the university's enrollment: freshman (28.4\%); sophomore (19.7\%); junior (20.9\%); senior (31.0\%). With respect to tanning behaviors, $64.9 \%$ reported current OT tanning, $50.7 \%$ reported ever IT, and $21.2 \%$ reported ever ST. Thirty percent of respondents self-identified as current IT. Demographic and other behavioral characteristics can be found in Table 1. Association between each tanning behavior and demographic and other behavioral characteristics are reported below.

\section{Outdoor tanning}

In the sample, 1732 individuals (64.9\%) reported OT. On multivariate analysis (Table 2$)$, being female $(\mathrm{OR}=1$. $75,95 \%$ CI $[1.39,2.20]) ;$ lifetime history of $1-2$ blistering sunburns $(\mathrm{AOR}=1.38,95 \% \mathrm{CI}[1.06,1.80])$; ever having ST $(\mathrm{AOR}=2.54,95 \%$ CI $[2.03,3.18])$; ever having IT $(\mathrm{AOR}=2.54,95 \% \mathrm{CI}[2.03,3.18])$; and intending to use tanning beds in the next 12 months (AOR $=10.63,95 \%$ CI $[5.38,20.98])$ were associated with increased likelihood of OT. Being Black/African American race (adjusted odds ratio $[\mathrm{AOR}]=0.05,95 \%$ confidence interval [CI] [0.03, 0.07]); "Other" race $(\mathrm{AOR}=0.42,95 \% \mathrm{CI}[0$. $30,0.58]$ ); Don't know/Not sure about immediate family history of melanoma $(\mathrm{OR}=0.67$; $95 \% \mathrm{CI}[0.51,0.88])$; Fitzpatrick skin type I/II (AOR $=0.19,95 \%$ CI $[0.13,0$. $29])$; and Fitzpatrick skin type III (OR $=0.59,95 \%$ CI $[0$. $40,0.86]$ were associated with decreased likelihood of OT. Age, college year, and state of residence were not significantly associated with OT. 
Table 1 Demographic characteristics for undergraduate students $(n=2668)$

\begin{tabular}{|c|c|}
\hline Variable & $N(\%)$ \\
\hline \multicolumn{2}{|l|}{ Age } \\
\hline 18 years old & $254(9.5)$ \\
\hline 19 years old & $509(19.1)$ \\
\hline 20 years old & $455(17.1)$ \\
\hline 21 years old & $410(15.4)$ \\
\hline $22+$ years old & $1040(39.0)$ \\
\hline \multicolumn{2}{|l|}{ College Year } \\
\hline Freshman & $555(20.8)$ \\
\hline Sophomore & $589(22.1)$ \\
\hline Junior & $723(27.1)$ \\
\hline Senior & $801(30.0)$ \\
\hline \multicolumn{2}{|l|}{ Sex } \\
\hline Male & $818(30.7)$ \\
\hline Female & $1844(69.3)$ \\
\hline \multicolumn{2}{|l|}{ Race } \\
\hline White & $1838(68.9)$ \\
\hline Black or African American & $480(18.0)$ \\
\hline Other & $350(13.1)$ \\
\hline \multicolumn{2}{|l|}{ Alabama resident } \\
\hline Yes & 2119 (79.6) \\
\hline No & $544(20.4)$ \\
\hline
\end{tabular}

Immediate family member with history of melanoma

$\begin{array}{lc}\text { No } & 2015(75.6) \\ \text { Yes } & 184(6.9) \\ \text { Don't know/Not sure } & 465(17.5)\end{array}$

Fitzpatrick score

Fitzpatrick Type I/II

$395(14.8)$

Fitzpatrick Type III

$780(29.3)$

Fitzpatrick Type IV

$875(32.8)$

Fitzpatrick Type VNI

$617(23.1)$

Number of lifetime blistering sunburns

$\begin{array}{lc}\text { None } & 955(35.8) \\ 1-2 & 1030(38.7) \\ 3-5 & 508(19.1) \\ 6 \text { or more } & 172(6.5) \\ \text { Outdoor tanner } & \\ \text { No } & 936(35.1) \\ \text { Yes } & 1732(64.9)\end{array}$

Ever spray tanned

No

$2033(78.2)$

Yes

$566(21.2)$

Ever indoor tanned
Table 1 Demographic characteristics for undergraduate students $(n=2668)$ (Continued)

\begin{tabular}{lc}
\hline \multicolumn{1}{c}{ Variable } & $N(\%)$ \\
\hline Yes & $1353(50.7)$ \\
Currently use tanning beds & $1054(69.6)$ \\
No & $461(30.4)$ \\
Yes & \\
Intend to use tanning bed next month & $2312(87.1)$ \\
No & $343(12.9)$ \\
Yes & \\
Intend to use tanning bed next 12 months & $2208(83.2)$ \\
No & $447(16.8)$ \\
Yes & $105(23.4)$ \\
Preferred method of tanning if time, convenience, and price not factors \\
Tanning beds & $267(59.5)$ \\
Tanning outdoors & $72(16.0)$ \\
Spray tan & $5(1.1)$ \\
Other &
\end{tabular}

\section{Indoor tanning}

Of the respondents, $1353(50.7 \%)$ reported ever IT. On multivariate analysis (Table 3), females and Alabama residents were also significantly more likely to have ever IT $(\mathrm{AOR}=1.65,95 \% \mathrm{CI}[1.34,2.04]$ and $\mathrm{AOR}=1.44,95 \%$ CI $[1.14,1.83]$, respectively). Lifetime history of blistering sunburns was also associated with greater likelihood of ever IT: reported history of $3-5$ burns (AOR $=1.36$, $95 \% \mathrm{CI}[1.01,1.83])$ and $6+$ burns $(\mathrm{AOR}=2.06,95 \% \mathrm{CI}$ $[1.33,3.20])$. Also associated with increased likelihood of ever IT were: self-reported OT $(\mathrm{AOR}=2.47,95 \%$ CI $[1$. 97, 3.10]); ever ST (AOR $=3.34,95 \%$ CI [2.51, 4.45]); and intending to IT in the next 12 months $(A O R=22$. 82, 95\% CI [12.85, 40.54]). Black/African American race and "Other" race were significantly associated with decreased likelihood of ever IT (AOR $=0.56,95 \%$ CI [0.39, $0.80]$ and $\mathrm{AOR}=0.68,95 \% \mathrm{CI}[0.50,0.94]$, respectively). Participants reporting, "Don't know/Not sure," of an immediate family history of melanoma also demonstrated decreased likelihood of ever having IT (AOR $=0.76,95 \%$ CI $[0.59,0.98])$. Participants $22+$ years old were $71 \%$ more likely to have ever IT $(\mathrm{AOR}=1.71,95 \% \mathrm{CI}[1.02$, 2.86]). College year and Fitzpatrick skin type were not significantly associated with IT history in the multivariate analysis.

\section{Spray tanning}

In the study sample, 566 participants (21.2\%) reported ever ST. On multivariate analysis (Table 4), characteristics significantly associated with increased likelihood of ST were: female sex $(\mathrm{AOR}=8.79,95 \% \mathrm{CI}[5.86,13.18]$; Fitzpatrick skin type I/II $(\mathrm{AOR}=1.78,95 \%$ CI $[1.11,2$. 
Table 2 Variables associated with self-reported outdoor tanning behavior among undergraduate students $(n=1732)$

\begin{tabular}{|c|c|c|c|c|c|}
\hline Variable & Outdoor Tans N (\%) & Odds Ratio & $95 \% \mathrm{Cl}$ & Adjusted Odds Ratio & $95 \% \mathrm{Cl}$ \\
\hline \multicolumn{6}{|l|}{ Age } \\
\hline 18 years old (ref) & $156(9.0)$ & 1.00 & & 1.00 & \\
\hline 19 years old & $324(18.7)$ & 1.10 & $0.81-1.50$ & 1.03 & $0.67-1.60$ \\
\hline 20 years old & $298(17.2)$ & 1.19 & $0.87-1.64$ & 0.86 & $0.50-1.48$ \\
\hline 21 years old & $303(17.5)$ & 1.78 & $1.27-2.49$ & 1.33 & $0.74-2.41$ \\
\hline $22+$ years old & $651(37.6)$ & 1.05 & $0.79-1.39$ & 0.58 & $0.33-1.00$ \\
\hline \multicolumn{6}{|l|}{ Year } \\
\hline Freshman (ref) & $336(19.4)$ & 1.00 & & 1.00 & \\
\hline Sophomore & $381(22.0)$ & 1.19 & $0.94-1.52$ & 1.15 & $0.78-1.69$ \\
\hline Junior & $471(27.2)$ & 1.22 & $0.97-1.53$ & 0.97 & $0.62-1.53$ \\
\hline Senior & $544(31.4)$ & 1.38 & $1.10-1.73$ & 1.33 & $0.82-2.14$ \\
\hline \multicolumn{6}{|l|}{ Sex } \\
\hline Male (ref) & $454(26.3)$ & 1.00 & & 1.00 & \\
\hline Female & $1274(73.7)$ & 1.79 & $1.51-2.12$ & 1.75 & $1.39-2.20$ \\
\hline \multicolumn{6}{|l|}{ Race } \\
\hline White (ref) & $1428(82.4)$ & 1.00 & & 1.00 & \\
\hline Black or African American & $85(4.9)$ & 0.06 & $0.05-0.08$ & 0.05 & $0.03-0.07$ \\
\hline Other & $219(12.6)$ & 0.48 & $0.38-0.61$ & 0.42 & $0.30-0.58$ \\
\hline \multicolumn{6}{|l|}{ Alabama Resident } \\
\hline Yes (ref) & $383(22.2)$ & 1.00 & & 1.00 & \\
\hline No & $1345(77.8)$ & 0.73 & $0.60-0.90$ & 0.79 & $0.61-1.03$ \\
\hline \multicolumn{6}{|c|}{ Immediate family member with history of melanoma } \\
\hline No (ref) & $1324(76.5)$ & 1.00 & & 1.00 & \\
\hline Yes & $130(7.5)$ & 1.26 & $0.90-1.75$ & 0.68 & $0.45-1.03$ \\
\hline Don't know/Not sure & $277(16.0)$ & 0.77 & $0.63-0.95$ & 0.67 & $0.51-0.88$ \\
\hline \multicolumn{6}{|l|}{ Fitzpatrick score } \\
\hline Fitzpatrick Type V/VI (ref) & $280(16.2)$ & 1.00 & & 1.00 & \\
\hline Fitzpatrick Type I/II & $225(13.0)$ & 1.60 & $1.23-2.08$ & 0.19 & $0.13-0.29$ \\
\hline Fitzpatrick Type III & $612(35.3)$ & 4.33 & $3.42-5.49$ & 0.59 & $0.40-0.86$ \\
\hline Fitzpatrick Type IV & $615(35.5)$ & 2.84 & $2.28-3.53$ & 0.88 & $0.64-1.22$ \\
\hline \multicolumn{6}{|c|}{ Number of lifetime blistering sunburns } \\
\hline None (ref) & $496(28.6)$ & 1.00 & & 1.00 & \\
\hline $1-2$ & $764(44.1)$ & 2.66 & $2.20-3.21$ & 1.38 & $1.06-1.80$ \\
\hline $3-5$ & $360(20.8)$ & 2.25 & $1.79-2.83$ & 1.07 & $0.77-1.48$ \\
\hline 6 or more & $112(6.5)$ & 1.73 & $1.23-2.42$ & 0.87 & $0.55-1.37$ \\
\hline \multicolumn{6}{|l|}{ Ever spray tanned } \\
\hline No (ref) & $1178(69.8)$ & 1.00 & & 1.00 & \\
\hline Yes & $510(30.2)$ & 6.61 & $4.95-8.83$ & 2.26 & $1.60-3.20$ \\
\hline \multicolumn{6}{|l|}{ Ever used a tanning bed } \\
\hline No (ref) & $572(34.0)$ & 1.00 & & 1.00 & \\
\hline Yes & $1111(66.0)$ & 5.33 & $4.46-6.37$ & 2.54 & $2.03-3.18$ \\
\hline \multicolumn{6}{|c|}{ Intend to use tanning bed next 12 months } \\
\hline No (ref) & $1287(74.7)$ & 1.00 & & 1.00 & \\
\hline Yes & $437(25.3)$ & 31.26 & $16.61-58.84$ & 10.63 & $5.38-20.98$ \\
\hline
\end{tabular}


Table 3 Variables associated with self-reported ever indoor tanning among undergraduate students $(n=1353)$

\begin{tabular}{|c|c|c|c|c|c|}
\hline Variable & Ever indoor tanned $N(\%)$ & Odds Ratio & $95 \% \mathrm{Cl}$ & Adjusted Odds Ratio & $95 \% \mathrm{Cl}$ \\
\hline \multicolumn{6}{|l|}{ Age } \\
\hline 18 years old (ref) & $104(7.7)$ & 1.00 & & 1.00 & \\
\hline 19 years old & $216(16.0)$ & 1.05 & $0.77-1.44$ & 0.97 & $0.64-1.48$ \\
\hline 20 years old & $211(15.6)$ & 1.27 & $0.92-1.74$ & 0.87 & $0.52-1.46$ \\
\hline 21 years old & $219(16.2)$ & 1.62 & $1.18-2.24$ & 1.06 & $0.61-1.84$ \\
\hline $22+$ years old & $603(44.6)$ & 2.00 & $1.51-2.66$ & 1.71 & $1.02-2.86$ \\
\hline \multicolumn{6}{|l|}{ Year } \\
\hline Freshman (ref) & $224(16.6)$ & 1.00 & & 1.00 & \\
\hline Sophomore & $272(20.1)$ & 1.30 & $1.02-1.65$ & 1.22 & $0.85-1.75$ \\
\hline Junior & $386(28.5)$ & 1.70 & $1.35-2.13$ & 1.43 & $0.93-2.18$ \\
\hline Senior & $471(34.8)$ & 2.11 & $1.69-2.64$ & 1.34 & $0.86-2.09$ \\
\hline \multicolumn{6}{|l|}{ Sex } \\
\hline Male (ref) & $294(21.8)$ & 1.00 & & 1.00 & \\
\hline Female & $1055(78.2)$ & 2.40 & $2.02-2.86$ & 1.65 & $1.34-2.04$ \\
\hline \multicolumn{6}{|l|}{ Race } \\
\hline White (ref) & $1111(82.1)$ & 1.00 & & 1.00 & \\
\hline Black or African American & $106(7.8)$ & 0.19 & $0.15-0.24$ & 0.56 & $0.39-0.80$ \\
\hline Other & $136(10.1)$ & 0.43 & $0.34-0.54$ & 0.68 & $0.50-0.94$ \\
\hline \multicolumn{6}{|l|}{ Alabama Resident } \\
\hline No (ref) & $252(18.7)$ & 1.00 & & 1.00 & \\
\hline Yes & 1099 (81.3) & 1.24 & $1.03-1.51$ & 1.44 & $1.14-1.83$ \\
\hline \multicolumn{6}{|c|}{ Immediate family member with history of melanoma } \\
\hline No (ref) & $1032(76.3)$ & 1.00 & & 1.00 & \\
\hline Yes & $118(8.7)$ & 1.65 & $1.20-2.26$ & 1.01 & $0.69-1.49$ \\
\hline Don't know/Not sure & $203(15.0)$ & 0.73 & $0.59-0.90$ & 0.76 & $0.59-0.98$ \\
\hline \multicolumn{6}{|l|}{ Fitzpatrick score } \\
\hline Fitzpatrick Type VNI (ref) & $205(15.2)$ & 1.00 & & 1.00 & \\
\hline Fitzpatrick Type I/II & $208(15.4)$ & 2.29 & $1.76-2.96$ & 0.83 & $0.56-1.23$ \\
\hline Fitzpatrick Type III & $477(35.3)$ & 3.11 & $2.49-3.89$ & 1.06 & $0.76-1.48$ \\
\hline Fitzpatrick Type IV & $463(34.2)$ & 2.26 & $1.82-2.81$ & 1.13 & $0.85-1.50$ \\
\hline \multicolumn{6}{|c|}{ Number of lifetime blistering sunburns } \\
\hline None (ref) & $368(27.2)$ & 1.00 & & 1.00 & \\
\hline $1-2$ & $571(42.2)$ & 2.00 & $1.67-2.40$ & 1.17 & $0.92-1.49$ \\
\hline $3-5$ & $305(22.5)$ & 2.40 & $1.92-3.07$ & 1.36 & $1.01-1.83$ \\
\hline 6 or more & $109(8.1)$ & 3.00 & $2.11-4.26$ & 2.06 & $1.33-3.20$ \\
\hline \multicolumn{6}{|l|}{ Outdoor tanner } \\
\hline No (ref) & $242(17.9)$ & 1.00 & & 1.00 & \\
\hline Yes & $1111(82.1)$ & 5.33 & $4.46-6.37$ & 2.47 & $1.97-3.10$ \\
\hline \multicolumn{6}{|l|}{ Ever spray tanned } \\
\hline No (ref) & $870(64.3)$ & 1.00 & & 1.00 & \\
\hline Yes & $483(35.7)$ & 7.70 & $6.00-9.87$ & 3.34 & $2.51-4.45$ \\
\hline \multicolumn{6}{|c|}{ Intend to use tanning bed next 12 months } \\
\hline No (ref) & $925(68.4)$ & 1.00 & & 1.00 & \\
\hline Yes & $428(31.6)$ & 43.53 & $24.90-76.07$ & 22.82 & $12.85-40.54$ \\
\hline
\end{tabular}


Table 4 Variables associated with self-reported spray tanning among undergraduate students $(n=566)$

\begin{tabular}{|c|c|c|c|c|c|}
\hline Variable & Ever spray tanned $N(\%)$ & Odds Ratio & $95 \% \mathrm{Cl}$ & Adjusted Odds Ratio & $95 \% \mathrm{Cl}$ \\
\hline \multicolumn{6}{|l|}{ Age } \\
\hline 18 years old (ref) & $45(8.0)$ & 1.00 & & 1.00 & \\
\hline 19 years old & $97(17.1)$ & 1.09 & $0.74-1.62$ & 1.42 & $0.86-2.34$ \\
\hline 20 years old & $94(16.6)$ & 1.22 & $0.82-1.81$ & 1.52 & $0.81-2.83$ \\
\hline 21 years old & $94(16.6)$ & 1.37 & $0.92-2.04$ & 1.32 & $0.67-2.59$ \\
\hline $22+$ years old & $236(41.7)$ & 1.36 & $0.95-1.94$ & 1.31 & $0.69-2.49$ \\
\hline \multicolumn{6}{|l|}{ Year } \\
\hline Freshman (ref) & $102(18.0)$ & 1.00 & & 1.00 & \\
\hline Sophomore & $110(19.4)$ & 1.03 & $0.76-1.39$ & 0.74 & $0.47-1.15$ \\
\hline Junior & $146(25.8)$ & 1.13 & $0.85-1.49$ & 0.76 & $0.45-1.31$ \\
\hline Senior & $208(36.7)$ & 1.55 & $1.18-2.02$ & 1.14 & $0.66-1.99$ \\
\hline \multicolumn{6}{|l|}{ Sex } \\
\hline Male (ref) & $28(5.0)$ & 1.00 & & 1.00 & \\
\hline Female & $536(95.0)$ & 11.54 & $7.81-17.05$ & 8.79 & $5.86-13.18$ \\
\hline \multicolumn{6}{|l|}{ Race } \\
\hline White (ref) & $503(88.9)$ & 1.00 & & 1.00 & \\
\hline Black or African American & $17(3.0)$ & 0.10 & $0.06-0.16$ & 0.35 & $0.19-0.64$ \\
\hline Other & $46(8.1)$ & 0.41 & $0.30-0.57$ & 0.79 & $0.53-1.19$ \\
\hline \multicolumn{6}{|l|}{ Alabama Resident } \\
\hline No (ref) & $116(20.5)$ & 1.00 & & 1.00 & \\
\hline Yes & $449(79.5)$ & 0.98 & $0.78-1.24$ & 0.97 & $0.74-1.28$ \\
\hline \multicolumn{6}{|c|}{ Immediate family member with history of melanoma } \\
\hline No (ref) & $428(75.6)$ & 1.00 & & 1.00 & \\
\hline Yes & $53(9.4)$ & 1.48 & $1.05-2.07$ & 1.05 & $0.71-1.55$ \\
\hline Don't know/Not sure & $85(15.0)$ & 0.83 & $0.64-1.08$ & 0.94 & $0.69-1.27$ \\
\hline \multicolumn{6}{|l|}{ Fitzpatrick score } \\
\hline Fitzpatrick Type V/NI (ref) & $59(10.4)$ & 1.00 & & 1.00 & \\
\hline Fitzpatrick Type I/II & $114(20.1)$ & 3.85 & $2.72-5.45$ & 1.78 & $1.11-2.86$ \\
\hline Fitzpatrick Type III & $217(38.3)$ & 3.55 & $2.60-4.85$ & 1.29 & $0.85-1.94$ \\
\hline Fitzpatrick Type IV & $176(31.1)$ & 2.36 & $1.72-3.24$ & 1.18 & $0.79-1.75$ \\
\hline \multicolumn{6}{|c|}{ Number of lifetime blistering sunburns } \\
\hline None (ref) & $122(21.6)$ & 1.00 & & 1.00 & \\
\hline $1-2$ & $250(44.2)$ & 2.18 & $1.72-2.77$ & 1.14 & $0.86-1.52$ \\
\hline $3-5$ & $147(26.0)$ & 2.78 & $2.12-3.65$ & 1.33 & $0.95-1.87$ \\
\hline 6 or more & $47(8.3)$ & 2.66 & $1.80-3.92$ & 1.32 & $0.82-2.13$ \\
\hline \multicolumn{6}{|l|}{ Outdoor tanner } \\
\hline No (ref) & $56(9.9)$ & 1.00 & & 1.00 & \\
\hline Yes & $510(90.1)$ & 6.61 & $4.95-8.83$ & 2.51 & $1.76-3.57$ \\
\hline \multicolumn{6}{|l|}{ Ever used a tanning bed } \\
\hline No (ref) & $83(14.7)$ & 1.00 & & 1.00 & \\
\hline Yes & $483(85.3)$ & 7.70 & $6.00-9.88$ & 3.27 & $2.45-4.37$ \\
\hline \multicolumn{6}{|c|}{ Intend to use tanning bed next 12 months } \\
\hline No (ref) & $343(60.6)$ & 1.00 & & 1.00 & \\
\hline Yes & $223(39.4)$ & 5.41 & $4.35-6.74$ & 2.04 & $1.57-2.65$ \\
\hline
\end{tabular}


86]); self-reported OT (AOR $=2.51,95 \% \mathrm{CI}[1.76,3.57])$; ever IT $(\mathrm{AOR}=3.27,95 \% \mathrm{CI}[2.45,4.37])$; and intending to IT in the next 12 months (AOR $=2.04,95 \% \mathrm{CI}[1.57$, 2.65]). Only Black/African American race was associated with decreased likelihood of ST (AOR $=0.35,95 \%$ CI $[0.19,0.64])$. Characteristics not associated with ST included: age, college year, state residence, immediate family history of melanoma, and number of lifetime blistering sunburns.

\section{Discussion}

The current study fills a significant gap in existing literature by examining multiple intentional tanning behaviors among a large population of undergraduates at a Southern, coastal university. While OT is a common tanning behavior, the rates and prevalence of $\mathrm{OT}$ are not well investigated in the literature, with varying categorizations of OT making comparisons between studies difficult. However, OT rates are higher in the current population (64.9\%) than those reported previously (34.4\% among 576 college students in Brooklyn, New York), likely due to proximity of the university to the beach [34]. IT rates of this study population (52.3\%) were comparable with other reported rates of undergraduate IT, including an international systematic review finding IT rates of 55\% among university students [15]. Sunless tanning product use has only been more recently examined in the literature, and comparisons are challenging because categories of these products can include both over-thecounter lotions and ST. Use of these products, particularly among adolescents and young adults have not been well-defined or investigated. In a 2004 national survey, $11 \%$ of U.S. adults claimed to have ever used sunless tanning products [35], while a more recent study examining the use of all sunless tanning products estimated use to be $25 \%$ among female teens (12-18) in the U.S. [36]. The current survey's rate of $21.2 \%$ is consistent with the usage among teens and provides a new benchmark for adolescents and young adults.

\section{Outdoor tanning}

As expected, results demonstrated that females are more likely to engage in OT than their male counterparts. This is not surprising given that females, particularly in this age range, are more likely than males to engage in all types of tanning behaviors, as previous studies have demonstrated [12, 21, 34]. Whites were also more likely to engage in OT than other races. This is supported by previous findings demonstrating greater OT rates among Whites compared with non-Whites [34]. Haluza et al. found that individuals with higher Fitzpatrick scores demonstrated lower motives to tan, likely due to their naturally darker skin tones [37]. Individuals with fairer skin may be more inclined to OT in the attempt to achieve the socially perceived attractiveness associated with tanned skin. This may explain the additional finding that lifetime history of $1-2$ sunburns was associated with greater likelihood of OT, as fairer skinned individuals are more likely to burn when exposed to UV radiation. More significantly, we found associations between tanning behaviors. Individuals who had ever ST were more than twice as likely to OT and individuals who had ever IT were 2.5 times as likely to OT. Further, those who reported the intention to IT in the next 12 months were over 10 times as likely to OT. These findings suggest there is a significant population of individuals that combine tanning behaviors, and the behaviors of this novel group of intentional combination tanners are not well understood.

\section{Indoor tanning}

We found that females were significantly more likely to IT than males, consistent with previous studies $[12,15,21,34]$, and that Whites were significantly more likely to IT than those of other races [38]. We also found that an increased number of blistering sunburns was proportionally associated with increased likelihood of IT, consistent with previous reports $[39,40]$. Additionally, an intention to IT in the next 12 months was strongly associated with history of IT. Interestingly, the results here demonstrate that those students who categorized themselves as residents of the state of Alabama were 1.4 times more likely to IT than non-Alabama residents, indicating potential sociocultural norms contributing to these students' tanning behaviors. Other types of tanning, including OT and ever ST were also significantly associated with ever IT, indicating again that there is an unexplored population of adolescents and young adults that engage in a combination of tanning behaviors.

\section{Spray tanning}

Research specifically on ST is sparse, though use of non-UV methods for tanning needs to be explored in adolescent and young adult populations. Interventions in recent years have attempted to promote sunless tanning as an alternative to UV (OT or IT) tanning [41, 42], and adoption of these practices among adolescents and young adults needs to be established to gauged the success of these efforts. Our results are consistent with reports of sunless tanning product use among teens 12-18 [36] and combination tanning, as reported in a study of 4601 individuals ages 18-34 years old [35], but this is the first report of ST usage among a large adolescent and young adult population. Females in this study were much more likely to engage in ST than males. Individuals with fairer skin tone and more prone to burning were also more likely to engage in ST, echoing previous research demonstrating an association between fair skin 
and sunless tanning product use [43]. This finding is likely related to negative experiences or low expectations regarding UV (or IT, specifically) tanning. Again, OT and IT behaviors were associated with a history of ST.

There was significant engagement in multiple tanning behaviors, or combination tanning, amongst this population [44]. While the most significant associations were with OT and IT [44], the correlation between IT and sunless tanning has not yet been made for adolescents and young adults. This behavior is consistent with combined IT and sunless tanning among adults [27, 45]. Some have hypothesized that engaging in both IT and $\mathrm{ST}$ is a consequence of commercial availability of both types of tanning in one, convenient location [35]. Given the use of these products among our surveyed population and their combination with UV tanning behaviors, more research is needed on the safety of sunless tanning product use regarding frequency and potential harmful effects associated with combining this behavior with other types of tanning.

The present study has many strengths, especially its large sample of over 2500 respondents, making it the largest college tanning study to date. Additionally, it examines a geographical population that has not been well-represented in the literature, as the majority of college tanning research has focused on Northeastern and Midwestern populations. It also identifies and quantities the use of multiple intentional tanning behaviors among this populations, while most work focuses on a single tanning behavior.

\section{Limitations}

Most participants were residents of Alabama or the South (79.6\%), therefore this sample is not necessarily representative of all college students throughout the United States. However, as noted above, this provides insight into a traditionally understudied and at-risk population. Due to gaps in the current literature, we are unable to determine the generalizability of these findings to the greater Gulf Coast region. While the survey response rate was approximately $25 \%$, this rate is comparable to rates of other electronic surveys in similar populations [33]. As with all surveys, there is the risk of self-report, recall, and other bias.

\section{Conclusions}

In this large survey of undergraduates from a Southern, coastal university we found significant engagement in tanning behaviors. More than half of the surveyed students engaged in OT and/or IT with a majority of tanners being white females. Further, there is an emerging population of ST, and again these tanners are predominantly white females. Of particular note is the high association between different tanning methods that indicates this population engages in multiple tanning behaviors. Combination tanning behaviors are not well understood and have not been well described in the literature, but this study suggests that these behaviors occur frequently. Given the literature associations between UV exposures and the risks associated with age of initiation and sex, our data suggest that white female tanners in the Southern U.S. may be at particular risk of developing skin cancer in the future and are prime candidates for interventions.

Future work in this area should focus on creating more standardized methodology and questions such as specific definitions of OT, IT, ST, and frequency to facilitate generalization and comparability of findings. New studies should also focus on the understudied trend of combination tanning (engaging in two or more types of tanning) demonstrated here with respect to predictors, long-term outcomes, and interventions targeting this type of behavior.

\section{Abbreviations}

AOR: Adjusted odds ratio; AYA: Adolescents and young adults;

Cl: Confidence interval; IT: Indoor tanning; OR: Odds ratio; OT: Outdoor tanning; ST: Spray tanning; US: United States; UV: Ultraviolet

\section{Acknowledgements}

The authors are greatly appreciative to the participating institution for its collaboration and assistance in coordinating and conducting this study.

\section{Funding}

No funding was received.

\section{Availability of data and materials \\ The dataset analyzed during the current study is available from the corresponding author on reasonable request.}

\section{Authors' contributions}

The contribution of authors was as follows: CD and MT conceptualized, designed, and conducted the study. NG also conceptualized the study and contributed to drafting the manuscript. SB conducted the statistical analyses and contributed to the drafting of the manuscript. AF assisted with conducting the study, the statistical analyses, and drafting of the manuscript. All authors read, contributed to, and approved the final manuscript.

\section{Ethics approval and consent to participate}

This study was deemed exempt by the Institutional Review Board (IRB) of the University of South Alabama. The IRB protocol number for this study is IRB \#854018-1. Individuals completed a written informed consent document prior to initiation of the survey stating the survey's purpose, voluntary and anonymous nature, details of participation, and contact information for the principal investigator.

\section{Consent for publication}

Not applicable

Competing interests

The authors declare that they have no competing interests.

\section{Publisher's Note}

Springer Nature remains neutral with regard to jurisdictional claims in published maps and institutional affiliations.

\section{Author details}

${ }^{1}$ Division of Oncological Sciences, University of South Alabama Mitchell

Cancer Institute, 1660 Springhill Avenue, Mobile, AL 36604, USA. ²Division of 
Preventive Medicine, Department of Medicine, University of Alabama at Birmingham, 1717 11th Avenue South, Birmingham, AL 35205, USA ${ }^{3}$ Comprehensive Cancer Center, University of Alabama at Birmingham, Birmingham, AL, USA. ${ }^{4}$ Department of Surgery, University of South Alabama College of Medicine, 2451 Fillingim Street, Mobile, AL 36617, USA.

\section{Received: 6 June 2017 Accepted: 21 March 2018}

Published online: 03 April 2018

\section{References}

1. ACS. Cancer Facts \& Figures 2016. Atlanta: American Cancer Society. p. 2016.

2. Misis DKL, Groman A, Beaupin LM, Salerno KE, Francescutti V, Skitzki JJ, Kane JM, Khushalani NI. Trends in demographics, incidence, and survival in children, adolescents, and young adults (AYA) with melanoma: a surveillance, epidemiology and end results (SEER) population-based analysis. 2015 ASCO Annual Meeting. Abstract 9058. Presented June 1, 2015. Chicago, IL.

3. Siegel RL, Miller KD, Jemal A. Cancer statistics, 2016. CA Cancer J Clin. 2016; 66(1):7-30.

4. Colantonio S, Bracken MB, Beecker J. The association of indoor tanning and melanoma in adults: systematic review and meta-analysis. J Am Acad Dermatol. 2014;70(5):847-57. e841-818

5. Lazovich D, Isaksson Vogel R, Weinstock MA, Nelson HH, Ahmed RL, Berwick M. Association between indoor tanning and melanoma in younger men and women. JAMA Dermatol. 2016;152(3):268-75.

6. Lazovich D, Vogel RI, Berwick M, Weinstock MA, Anderson KE, Warshaw EM. Indoor tanning and risk of melanoma: a case-control study in a highly exposed population. Cancer Epidemiol Biomark Prev. 2010;19(6): 1557-68.

7. Ting W, Schultz K, Cac NN, Peterson M, Walling HW. Tanning bed exposure increases the risk of malignant melanoma. Int J Dermatol. 2007;46(12):1253-7.

8. Wehner MR, Shive ML, Chren MM, Han J, Qureshi AA, Linos E. Indoor tanning and non-melanoma skin cancer: systematic review and metaanalysis. BMJ. 2012;345:e5909

9. Banerjee SC, Hay JL, Greene K. College students' cognitive rationalizations for tanning bed use: an exploratory study. Arch Dermatol. 2012;148(6):761-2.

10. Dennis LK, Lowe JB. Does artificial UV use prior to spring break protect students from sunburns during spring break? Photodermatol Photoimmunol Photomed. 2013;29(3):140-8.

11. Hillhouse J, Turrisi R, Holwiski F, McVeigh S. An examination of psychological variables relevant to artificial tanning tendencies. J Health Psychol. 1999;4(4):507-16.

12. Neenan A, Lea CS, Lesesky EB. Reasons for tanning bed use: a survey of community college students in North Carolina. N C Med J. 2012;73(2):89-92.

13. Russo VA, Van Acker MM, Vander Wal JS, Sinha AA. Patterns of use of sunless tanning product alternatives to indoor tanning among female college students. Arch Dermatol. 2012;148(7):855-7.

14. Sahn RE, Mcllwain MJ, Magee KH, Veledar E, Chen SC. A cross-sectional study examining the correlation between sunless tanning product use and tanning beliefs and behaviors. Arch Dermatol. 2012;148(4):448-54.

15. Wehner MR, Chren MM, Nameth D, Choudhry A, Gaskins M, Nead KT, Boscardin WJ, Linos E. International prevalence of indoor tanning: a systematic review and meta-analysis. JAMA Dermatol. 2014;150(4):390-400

16. Cafri G, Thompson JK, Jacobsen PB. Appearance reasons for tanning mediate the relationship between media influence and UV exposure and sun protection. Arch Dermatol. 2006;142(8):1067-9.

17. Cafri G, Thompson JK, Roehrig M, van den Berg P, Jacobsen PB, Stark S. An investigation of appearance motives for tanning: the development and evaluation of the physical appearance reasons for tanning scale (PARTS) and its relation to sunbathing and indoor tanning intentions. Body image. 2006;3(3):199-209.

18. Hillhouse J, Thompson JK, Jacobsen PB, Hillhouse J. Investigating the role of appearance-based factors in predicting sunbathing and tanning salon use. J Behav Med. 2009;32(6):532-44.

19. Prior SM, Fenwick KD, Peterson JC. Adolescents' reasons for tanning and appearance motives: a preliminary study. Body image. 2014;11(1):93-6.

20. Yoo JJ, Hur WM. Body-tanning attitudes among female college students. Psychol Rep. 2014;114(2):585-96.

21. Basch $\mathrm{CH}$, Hillyer GC, Basch CE, Neugut Al. Improving understanding about tanning behaviors in college students: a pilot study. J Am Coll Health. 2012; 60(3):250-6
22. Carcioppolo N, Orrego Dunleavy V, Yang Q. How do perceived descriptive norms influence indoor tanning intentions? An application of the theory of normative social behavior. Health Commun. 2016:1-10.

23. Gillen MM, Markey CN. The role of body image and depression in tanning behaviors and attitudes. Behav Med. 2012;38(3):74-82.

24. Heckman CJ, Darlow SD, Kloss JD, Munshi T, Manne SL. Contextual factors, indoor tanning, and tanning dependence in young women. Am J Health Behav. 2015;39(3):372-9.

25. Hemrich A, Pawlow L, Pomerantz A, Segrist D. Current versus ideal skin tones and tanning behaviors in Caucasian college women. J Am Coll Health. 2014:62(8):588-91.

26. Dunn MS. Does university selection and geographical region of birth influence tanning behaviors, tanning beliefs, and sunscreen barriers. Am J Health Stud. 2014;29(2):182-90.

27. Lazovich D, Stryker JE, Mayer JA, Hillhouse J, Dennis LK, Pichon L, Pagoto S, Heckman C, Olson A, Cokkinides V, et al. Measuring nonsolar tanning behavior: indoor and sunless tanning. Arch Dermatol. 2008;144(2):225-30.

28. Qureshi AA, Laden F, Colditz GA, Hunter DJ. Geographic variation and risk of skin cancer in US women. Differences between melanoma, squamous cell carcinoma, and basal cell carcinoma. Arch Intern Med. 2008;168(5):501-7.

29. The Surgeon General's Call to Action to Prevent Skin Cancer [http://www. surgeongeneral.gov/library/calls/prevent-skin-cancer/exec-summary.html]. Accessed 26 Mar 2018

30. Guy GP Jr, Berkowitz Z, Tai E, Holman DM, Everett Jones S, Richardson LC. Indoor tanning among high school students in the United States, 2009 and 2011. JAMA Dermatol. 2014;150(5):501-11.

31. Fitzpatrick TB. The validity and practicality of sun-reactive skin types I through VI. Arch Dermatol. 1988;124(6):869-71.

32. Kaplowitz MD, Hadlock TD, Levine R. A comparison of web and mail survey response rates. Public Opin Q. 2004;68(1):94-101.

33. Nulty DD. The adequacy of response rates to online and paper surveys: what can be done? Assess Eval Higher Educ. 2008;33(3):301-14

34. Fogel J, Krausz F. Watching reality television beauty shows is associated with tanning lamp use and outdoor tanning among college students. J Am Acad Dermatol. 2013;68(5):784-9.

35. Stryker JE, Yaroch AL, Moser RP, Atienza A, Glanz K. Prevalence of sunless tanning product use and related behaviors among adults in the United States: results from a national survey. J Am Acad Dermatol. 2007;56(3):387-90.

36. Quinn M, Alamian A, Hillhouse J, Scott C, Turrisi R, Baker K. Prevalence and correlates of indoor tanning and sunless tanning product use among female teens in the United States. Prev Med Rep. 2015;2:40-3.

37. Haluza D, Simic S, Holtge J, Cervinka R, Moshammer H. Gender aspects of recreational sun-protective behavior: results of a representative, populationbased survey among Austrian residents. Photodermatol Photoimmunol Photomed. 2016;32(1):11-21.

38. Buller DB, Cokkinides V, Hall HI, Hartman AM, Saraiya M, Miller E, Paddock L, Glanz K. Prevalence of sunburn, sun protection, and indoor tanning behaviors among Americans: review from national surveys and case studies of 3 states. J Am Acad Dermatol. 2011;65(5 Suppl 1):S114-23.

39. (CDC) CfDCaP. Use of indoor tanning devices by adults-United States, 2010. MMWR. 2012;61(18):323-6.

40. Stapleton JL, Hillhouse J, Turrisi R, Robinson JK, Baker K, Manne SL, Coups EJ Erythema and ultraviolet indoor tanning: findings from a diary study. Transl Behav Med. 2013;3(1):10-6.

41. Pagoto SL, Schneider KL, Oleski J, Bodenlos JS, Ma Y. The sunless study: a beach randomized trial of a skin cancer prevention intervention promoting sunless tanning. Arch Dermatol. 2010:146(9):979-84.

42. Paul CL, Paras L, Harper A, Coppa K. Harm minimization in tan seekers: an exploration of tanning behaviour and the potential for substitutional use of sunless tanning products. J Health Psychol. 2011;16(6):929-37.

43. Christensen DK, Dennis LK, Lynch CF, Smith EM, Snetselaar LG. Sunless tanning product use as related to UV protective behaviors among young adults. Invest Dermatol Venereol Res. 2015;1(2):1-6.

44. Tan MCB, Gassman NR, Fernandez AM, Bae S, Daniel CL. High prevalence of combination tanning among undergraduates: survey at a southeastern US university. J Am Acad Dermatol. 2017:77(5):968-70.

45. Cokkinides VE, Bandi P, Weinstock MA, Ward E. Use of sunless tanning products among US adolescents aged 11 to 18 years. Arch Dermatol. 2010; 146(9):987-92 